\title{
Twenty Years of the EU-Turkey Customs Union: A Synthetic Control Method Analysis ${ }^{*}$
}

\author{
HÜSEYIN AYTUĞ, ${ }^{1}$ MERVE MAVUȘ KÜTÜK, ${ }^{2}$ ARIF ODUNCU ${ }^{2}$ and SÜBIDEY TOGAN ${ }^{3}$ \\ ${ }^{1}$ Gulf Monetary Council ${ }^{2}$ Central Bank of the Republic of Turkey ${ }^{3}$ Bilkent University
}

\begin{abstract}
The paper studying the 1995 EU-Turkey Customs Union (CU) delivers a quantitative assessment of trade and GDP per capita effects of the CU on the Turkish economy. Our Synthetic Control Method based analysis reveals, contrary to the results of most studies in the literature, that the CU's effects have been substantial by any standards. In particular, the paper shows that in the absence of the EU-Turkey CU, Turkish exports to the EU and GDP per capita would have been 38 per cent and 13 per cent less, respectively.
\end{abstract}

Keywords: economic integration; trade agreements; synthetic control method

\section{Introduction}

In 1959, Turkey applied for associate membership of the then-European Economic Community (EEC). The application resulted in an Association Agreement (the Ankara Agreement) between the EEC and Turkey in 1963, whereby the parties agreed to create, inter alia, a Customs Union (CU). The CU was established on 1 January 1996 through the European Union (EU)-Turkey Association Council Decision 1/95, covering industrial goods including processed agricultural commodities but excluding European Coal and Steel Community (ECSC) products. A free trade agreement (FTA) between the ECSC and Turkey was signed on 29 February 1996, with European Commission Decision 96/528/ECSC covering the ECSC products.

Twenty years have passed since the start of the EU-Turkey CU, and it is time for an ex-post assessment. In this paper we provide such an assessment using the microeconometric technique of the Synthetic Control Method (SCM), developed by Abadie and Gardeazabal (2003) and Abadie et al. (2010). Our main contribution is that this is the first paper, as far as we know, using SCM in assessing the impact of the EU-Turkey CU.

The structure of the paper is as follows: Section 1 studies what the CU has meant for Turkey, and section 2 explains the SCM. Section 3 shows the results and robustness checks using the SCM. The final section concludes.

\subsection{European Union-Turkey Customs Union}

The EU-Turkey CU Decision (CUD) of 1995 required Turkey to eliminate all customs duties, quantitative restrictions, charges with an equivalent effect to customs duties, and all measures with an equivalent effect to quantitative restrictions in the trade of industrial

\footnotetext{
*The views expressed herein are solely of the authors and do not necessarily reflect those of the Central Bank of the Republic of Turkey or its staff.
} 
goods with the EU as of 1 January 1996. In addition, Turkey was required to adopt the EU's Common Customs Tariff (CCT) on third-country imports and adopt all the preferential agreements the EU had/has concluded and would/will conclude with third countries. Thus, over time, Turkey has concluded FTAs with Israel, Macedonia, Bosnia-Herzegovina, Palestine, Tunisia, Morocco, Syria, Egypt, Albania, Georgia, Montenegro, Serbia, Chile, Jordan, Mauritius, South Korea and Malaysia. As a result of the CU Turkey's economy-wide nominal protection rate (NPR) in trade with the EU as well as with third countries has decreased substantially. ${ }^{1}$ Regarding access to the Turkish market, almost all countries in the world have benefited from NPR reductions in Turkey. On the other hand, regarding access of Turkish goods to the EU market, note that the EU had abolished nominal tariff rates on imports of industrial goods from Turkey on 1 September 1971. In addition to tariffs and related issues, the EU-Turkey CU requirements extend to rules and disciplines on various regulatory border and behind-the-border policies, such as customs modernization, eliminating technical barriers to trade (TBTs), competition policies, intellectual property rights and trade policy instruments.

Prior to the formation of the CU, Turkey had a complicated import regime. The customs administration was a traditional paper-based organization and declarants had to go to customs offices to register declarations. Since almost all shipments had to be physically inspected, the process at customs was very intrusive and time consuming. It often led traders to pay substantial facilitation money to speed up the process or to curry favour with customs officials in charge of their inspections. On the other hand, until the formation of the $\mathrm{CU}$, Turkey did not have the quality infrastructure required for the elimination of TBTs nor the required technical knowledge. The state monopoly Turkish Standards Institute (TSE) was the National Standardization Body, provider of services for quality testing and accreditation services, and the authority setting technical regulations. The quality infrastructure was not linked up with international networks, and any accreditation granted by the Turkish accreditation body was not recognized internationally. Similarly, until the adoption of the EU-Turkey CU, Turkey had no specific competition legislation and thus no competition policy enforcement. Similar considerations hold for the protection of intellectual property rights. Finally, note that prior to the formation of the CU, Turkey did not have rules and regulations on anti-dumping, countervailing duties, surveillance, safeguards measures, administering quantitative quotas and procedures for officially supported export credits as in the EU.

With the CU Turkey has modernized its customs administration and adopted a new customs law similar to the EC's Customs Code. To eliminate the TBTs Turkey to a very large extent has harmonized its standards with European and international standards, harmonized its technical legislation with that of the EU, established the quality infrastructure comparable to the EU's, encompassing the operators and operation of testing, certification, inspection, accreditation and metrology, and developed a market surveillance and import control system as in the EU. Harmonization with EU regulations comprised both New and Old Approach directives and mutual recognition in the non-harmonized area. In the case of competition policy Turkey with the CU has adopted EU competition rules, including measures regarding public aid. In the case of protection of intellectual property rights, the country with the $\mathrm{CU}$ established the Patent Office, and has made substantial

\footnotetext{
${ }^{1}$ See Togan (1997).
} 
efforts to align its legislation with the acquis. Finally, note that Turkey since the formation of the CU has successfully adopted the EU rules and regulations on trade policy instruments and is effectively implementing them. These are remarkable achievements. The reforms have decreased trade costs substantially in trade between the EU and Turkey, and improved market access conditions for Turkish exports into the EU as well as for EU exports into Turkey. However, there are still areas where Turkey needs further alignment of its legislation and implementation with the acquis as emphasized recently by the European Commission (2015).

The EU-Turkey CU of 1995 has been a major instrument of integration into the EU and global markets for Turkey, offering the country powerful tools to reform its economy. It has credibly locked Turkey into a liberal foreign trade regime for industrial goods and holds the promise of Turkey's participation in the EU internal market for industrial products. As a result, Turkish producers of industrial goods have become exposed to competition from imports and they operate within one of the largest FTAs for industrial products in the world. They are now protected by tariffs from external competition to exactly the same extent that EU producers are, and as such, face competition from duty-free imports of industrial goods from world-class pan-European firms. In return, Turkish industrial producers have duty-free market access to the European Economic Area.

The existing literature on the effects of the EU-Turkey CU includes both ex-ante studies and ex-post studies. While the ex-ante studies are in general of computable general equilibrium (CGE) type, the ex-post studies mostly use gravity models to assess the impacts of the $\mathrm{CU}$ on trade and welfare. One of the earliest ex-ante studies of the EU-Turkey CU is that by Harrison et al. (1997). Using a CGE model, the authors conclude that the CU generates welfare gains for Turkey of 1-1.5 per cent of its GDP. On the other hand, Mercenier and Yeldan (1997) argue that the CU reduces welfare in Turkey. In a more recent ex-ante study, Lejour and de Mooij (2005) estimate the effects of the EU-Turkey $\mathrm{CU}$ for both the EU countries and Turkey. On the basis of a CGE model for the world economy, the authors find that the effect of Turkey's accession to the single market is substantial and positive for Turkey, and negligible for the EU-15. Among the ex-post studies, the findings of Antonucci and Manzocchi (2006) and Bilici et al. (2008) reveal that the EU-Turkey CU does not have any role to promote additional trade between parties. In contrast, Adam and Moutos (2008), Nowak-Lehmann et al. (2007) and Neyaptı et al. (2007) support positive impacts of the $\mathrm{CU}$ on trade flows. Furthermore, two recent studies which are the only ones using the gravity model based on the theoretical foundations of Anderson and van Wincoop (2003) are of major importance. The World Bank (2014) estimates a gravity model using a dummy variable for the EU-Turkey CU. The coefficient estimate for average treatment effect was 0.2 suggesting a 22 per cent increase in bilateral trade due to the CU, though this effect was not statistically significant. ${ }^{2}$ On the other hand,

\footnotetext{
${ }^{2}$ The World Bank report emphasizes that empirically it is difficult to argue that the CU has caused a major shift in relative trade shares for Turkey because the EU had already opened its markets for Turkish exports of industrial goods long before the CU came into effect. Furthermore, the study notes that a potential FTA between the EU and Turkey as opposed to the present EU-Turkey CU would lead to significant reductions in EU imports from Turkey. The study further reveals that Turkey's real income would increase with the finalization of non-compliant FTAs such as those with Mexico, South Africa, Columbia, Peru, Panama, Costa Rica, Guatemala, El Salvador, Honduras and Nicaragua. Finally, the report shows that successful conclusion of the Transatlantic Trade and Investment Partnership between the EU and the United States while excluding Turkey would adversely affect Turkey's terms of trade and welfare.
} 
Magee (2015) concludes that the CU has generated more than twice as much trade creation as trade diversion, but that the overall impact of the CU has been relatively small. ${ }^{3}$

It is important to note that in the framework of the EU-Turkey CU, Turkey has not only eliminated tariffs and quotas on the trade of industrial commodities with the EU but has also adopted EU rules and regulations on customs, TBTs, competition policies, intellectual property rights and trade policy instruments. Therefore, the CU can be seen as the prior step for Turkey's EU integration but this integration may not end up with full membership of EU since an open-ended membership framework has been introduced after the enlargement of 2004 (Karakas, 2013; Ugur, 2010). The general consensus in Turkey on the $\mathrm{CU}$ is that it has been beneficial for the country not only because of trade creation effects of the $\mathrm{CU}$ due to lower tariffs but also due to welfare increasing steps towards an economy with high integration with the global economic system and effective institutions enhancing developments. Since these beneficial indirect effects could not be estimated using earlier methods (such as gravity models), we use the micro-econometric SCM in this paper to determine the concrete benefits/losses the EU-Turkey CU has generated for Turkey by concentrating on the CU's effects on trade and the GDP

\section{Synthetic Control Method}

Abadie and Gardeazabal (2003) employ SCM to evaluate the effect of terrorism in Spain, while Abadie et al. (2010) estimate the impact of California's programme to reduce tobacco consumption in California. Lee (2011) investigates the success of inflation targeting in reducing inflation rates and Billmeier and Nannicini (2013) evaluate the impact of economic liberalization on GDP per capita. The idea behind SCM is to approximate the relevant characteristics of the country affected by an intervention using a weighted combination of potential control countries, which is the synthetic control. The SCM can be used to estimate the counterfactual situation in the country by using the synthetic control in the absence of the intervention. The counterfactual shows what the outcome of the affected country would have been if the intervention had not happened. In our case, the synthetic control helps us answer what the level of exports to the EU and the GDP per capita in Turkey would have been if the EU-Turkey CU had not been established. ${ }^{4}$

Formally, the general idea behind the SCM is as follows: Let $Y_{i t}^{0}$ be the outcome (exports or GDP per capita) that would be observed for country $i$ (Turkey) at time $t$ in the absence of the intervention (membership in the CU) for units $i=1, \ldots, J+1$ and time periods $t=1, \ldots, T$. Let $T_{0}$ be the intervention period, where $1 \leq T_{0} \leq T$. Let $Y_{i t}^{1}$ be the outcome observed for country $i$ at time $t$ when the country is exposed to the intervention between periods $T_{0}+1$ and $T$. Then, the treatment effect (the impact of the intervention) for country $i$ can be defined as $\tau_{i t}=Y_{i t}^{1}-Y_{i t}^{0}$. However, $Y_{i t}^{1}$ is observed and $Y_{i t}^{0}$ is not

\footnotetext{
${ }^{3}$ A regional trade agreement (RTA) creates a preference favouring trade with an RTA partner country, whose imports face no tariffs, over other countries whose imports are taxed. When imports from low-cost countries outside the regional trading area are replaced by imports from higher cost countries within the RTA, we talk of trade diversion. On the other hand, trade creation is generated when the lower tariffs within the trading block allow inefficient domestic production to be replaced by cheaper imports from a preferential trading partner.

${ }^{4}$ We initially intended to study the effects of the CU on Foreign Direct Investment (FDI) flows as well. However, this could not be accomplished because of the lack of data on bilateral FDI flows in Turkey.
} 
observed between $T_{0}+1$ and $T$. Thus, $Y_{i t}^{0}$, which is the counterfactual, must be estimated to find the impact of the intervention.

Abadie et al. (2010) show how to identify the treatment effect, $\tau_{i t}$, using the following model for potential outcomes:

$$
\begin{gathered}
Y_{i t}^{0}=\delta_{t}+Z_{i} \Theta_{t}+\lambda_{t} \mu_{i}+\varepsilon_{i t} \\
Y_{i t}^{1}=\delta_{t}+\tau_{i t}+Z_{i} \Theta_{t}+\lambda_{t} \mu_{i}+\varepsilon_{i t},
\end{gathered}
$$

where $Z_{i}$ is a vector of relevant observed covariates (either time-varying or timeinvariant) that are not affected by the intervention, $\Theta_{t}$ a vector of parameters, $\lambda_{t}$ an unknown common factor, $\mu_{i}$ a country-specific unobservable, $\varepsilon_{i t}$ a transitory shock with a zero mean, and $\tau_{i t}$ a dummy variable that takes the value 1 for the treated unit, and 0 otherwise.

Suppose that the first country (Turkey), $i=1$, receives the treatment (membership in the $\mathrm{CU}$ ) and the remaining $J$ countries, $i=2, \ldots, J+1$, do not. The proposed data-driven approach is to approximate $Y_{i t}^{0}$ by a weighted average of $Y_{i t}^{1}$, taking into account the covariates $Z$ for the pre-intervention period, $t \leq T_{0}$, such that:

$$
\begin{aligned}
& Y_{1 t}=\sum_{i=2}^{J+1} w_{i}^{*} Y_{i t} \\
& Z_{1}=\sum_{i=2}^{J+1} w_{i}^{*} Z_{i},
\end{aligned}
$$

where the weights, $w_{i}$, satisfy $\sum_{i=2}^{J+1} w_{i}=1$ and $w_{i} \geq 0$. These two assumptions for the weights make sure that there is no extrapolation of outcomes from the model. Finally, the treatment effect can be estimated using:

$$
\widehat{\tau_{i t}}=Y_{1 t}-\sum_{i=2}^{J+1} w_{i}^{*} Y_{i t} \text { for } t=T_{0}+1, \ldots, T \text {. }
$$

The main idea here is that the synthetic control imitates the counterfactual of the treated country that would have been observed in the absence of the intervention using 
the weighted average of all control countries. For the optimal choice of $W^{*}$, consider $X_{1}=\left(Z_{1}, Y_{11}, \ldots, Y_{1 T_{0}}\right)$ to be the vector of pre-intervention characteristics for country $i=1$, and $X_{0}=\left(Z_{j}, Y_{j t}, \ldots, Y_{j T_{0}}\right)$ to be the matrix of the same characteristics for the control units $j \in[2, j+1]$. Then the vector $W^{*}$ is chosen to minimize the distance between $X_{1}$ and $X_{0} W$, following:

$$
\begin{gathered}
\min _{W}|| X_{1}-X_{0} W \|_{v}=\min _{W(V)} \sqrt{\left(X_{1}-X_{0} W\right)^{\prime} V\left(X_{1}-X_{0} W\right)} \\
\text { s.t. } w_{i} \geq 0 \text { for } i=2, \ldots, J+1 \text { and } \sum_{i=2}^{J+1} w_{i}=1,
\end{gathered}
$$

where $V$ is a $k \times k$ symmetric and positive semi-definite matrix, which measures the relative importance of the pre-intervention characteristics included in $X$. Thus, $W$ is a function of the elements of $V$. The minimization problem above provides a solution for $W^{*}\left(V^{*}\right)$ that minimizes the pre-intervention Root Mean Square Prediction Error (RMSPE) of the outcome over the control period. Thus, the accuracy of the approximation depends on the minimization problem, which is satisfied with a lower RMSPE. In other words, the SCM estimates the unobserved counterfactual as a weighted average of the outcomes of the control countries, with weights chosen to approximate the pre-intervention characteristics of the affected country.

In the choice of control countries, two important assumptions are made. First, the preintervention characteristics, $X_{1}$, should include variables that can approximate the affected country but cannot anticipate the effects of the intervention. For instance, if Turkey's preintervention characteristics can anticipate the effects of the European CU, the synthetic Turkey would generate a lower-bound estimate because some part of the real effect occurs before the formation of the CU. Second, the control countries, $Y_{i t}$, used in the minimization problem must not be affected by the intervention. For instance, if a European country is chosen as a control country, Turkey's involvement in the EU-Turkey CU will be definitely affected by this country. Thus, the control countries should not affect the EU-Turkey CU Decision.

Compared to other comparative methods (panel data or difference-in-differences), the SCM has some evident advantages. In other methods, control units are chosen on the basis of subjective measures. However, the SCM is data-driven and it chooses control units that can best approximate the affected unit. Another shortcoming of other methods is that it is not possible to test whether any of the control units can replicate the evolution of the affected unit's outcome. In the SCM, as Abadie et al. (2010) suggest, placebo experiments can be implemented to make inferences by reassigning the intervention to each control unit and estimating the intervention effect for each unit. In addition, we can compare the results with baseline results. In other words, we can assess whether the baseline results for the treated unit are larger than the effects for countries chosen at random. Finally, one of the important advantages of the SCM over panel data models 
is that the effect of unobserved heterogeneity does not have to be time-invariant and independent of the error term, as implied by equation 1 . In contrast, panel-data models control only for confounding factors that are time-invariant (fixed effect) or share a common trend (difference-in-differences). The SCM method can handle endogeneity due to a time-varying omitted bias.

\section{Results}

To analyze what the Turkish export growth to the EU and Turkish GDP per capita would have been if the EU-Turkey CU had not been established, two independent estimates are made using the SCM.

First of all, the growth of Turkish exports to 28 EU Member States is taken into consideration. Export growth (the outcome variable) is estimated using characteristic variables of the control countries, namely real GDP, distance to the EU, and countries' areas, chosen in line with the Gravity Model framework. ${ }^{5}$ All combinations of control countries are used to achieve the best match to the realized growth of Turkish exports to the EU and Turkey's characteristic variables before the treatment period, specifically, pre-1996, before the formation of the CU.

The best match for Turkey's realized export growth (outcome variable) and the other characteristic variables (such as, minimum distance between synthetic and realized outcome and characteristic variables), is achieved with the related weight of control countries shown in Table 1. These weights for those control countries are obtained as a result of the minimization problem described in equations 6 and 7. Following the minimization process, not only Turkey's synthetic export growth but also synthetic characteristic variables (real GDP, distance to EU, and area) are also calculated, using the weights for each control country. As evident from Table 2, the gaps between actual and synthetic outcomes and the characteristic variables are quite small.

Table 1: Country Weights for the Synthetic Controls

\begin{tabular}{lcc}
\hline Country & Growth of Exports & GDP per capita \\
Argentine & 0 & 0 \\
Brazil & 0.12 & 0.04 \\
Chile & 0.41 & 0.18 \\
Colomboa & 0 & 0 \\
India & 0.14 & 0.06 \\
Indonesia & 0.33 & 0.07 \\
Mexico & 0 & 0.47 \\
South Africa & 0 & 0.19 \\
\hline
\end{tabular}

\footnotetext{
${ }^{5}$ The empirical literature explaining trade flows based on gravity models explains exports mainly by real GDP, bilateral distance between countries, and area. The other explanatory variables used in gravity models are binary variables for common language, membership of a regional trade agreement, common border and common colonial history. However, the latter set of variables could not be used as characteristic variables due to the methodological properties of the SCM. For studies using the variable of countries' areas, see Glick and Rose (2002), Longo and Senkat (2004) and Soloaga and Winters (2001).
} 
Both the realized and synthetic export growth increases are shown in panel (a) of Figure 1. As illustrated by the graph, there is quite a close match before the treatment period (1989-95). After the treatment period, the series labelled 'synthetic Turkey' shows what the estimated Turkish export growth to the EU would have been if the EU-Turkey $\mathrm{CU}$ had not been established. From the figure, it is clear that the realized export growth is higher than the synthetic one for most years, especially after 2005. This result suggests that the growth of Turkey's exports to the EU would have been lower without the formation of the EU-Turkey CU. ${ }^{6}$

We repeated the minimization process of both the outcome and characteristic variables in order to estimate the level of per capita GDP in Turkey without the EU-Turkey CU. In this case, as suggested by the growth literature, the characteristic variables are comprised of the ratio of current account balance to GDP in 1990, share of investment in GDP in 1990 and the industry value added in GDP in 1991, population growth in 1995, average number of years of education received by people aged 25 years and older in 1995, and inflation rate in 1992. ${ }^{7}$ We tried to match those variables as closely as possible using the country weights obtained as a result of the minimization process, displayed in the third column of Table 1. As shown in Table 3, the actual and synthetic series are close to each other before the treatment. The estimated and actual real GDP values per capita in Turkey throughout the whole period are depicted in panel (b) of Figure 1. The movement and levels of the actual and synthetic series suggest that although the actual series is higher than the synthetic one in some years at the beginning of treatment period, Turkey's real GDP per capita would have been lower,

Table 2: Predictor Balance for Growth of Exports.

\begin{tabular}{llc}
\hline Variable & Actual & Synthetic \\
GDP(1989) & 25.4 & 25.13 \\
GDP(1990) & 25.74 & 25.23 \\
GDP(1991) & 25.74 & 25.29 \\
GDP(1992) & 25.79 & 25.4 \\
GDP(1993) & 25.92 & 25.48 \\
GDP(1994) & 25.6 & 25.63 \\
GDP(1995) & 25.86 & 25.83 \\
Area & 13.57 & 14.34 \\
Distance to the EU & 7.44 & 9.24 \\
Exports to the EU/GDP(1989) & 5.48 & 1.33 \\
Exports to the EU/GDP(1990) & 4.93 & 5.69 \\
Exports to the EU/GDP(1991) & 5.11 & 5.02 \\
Exports to the EU/GDP(1992) & 5.3 & 4.65 \\
Exports to the EU/GDP(1993) & 4.6 & 3.92 \\
Exports to the EU/GDP(1994) & 7.2 & 3.74 \\
Exports to the EU/GDP(1995) & 7.22 & 4.17 \\
\hline
\end{tabular}

\footnotetext{
6 The graph of Turkey's realized and synthetic export to the EU is shown in the Appendix.

${ }^{7}$ In line with the empirical growth literature (for example, Barro, 1991), shares of industry and investment in GDP, population growth rate, ratio of current account balance to GDP, average schooling years, and inflation rates are used as characteristic variables for the outcome variables of real GDP per capita.
} 
Figure 1: Synthetic Controls. [Colour figure can be viewed at wileyonlinelibrary.com]

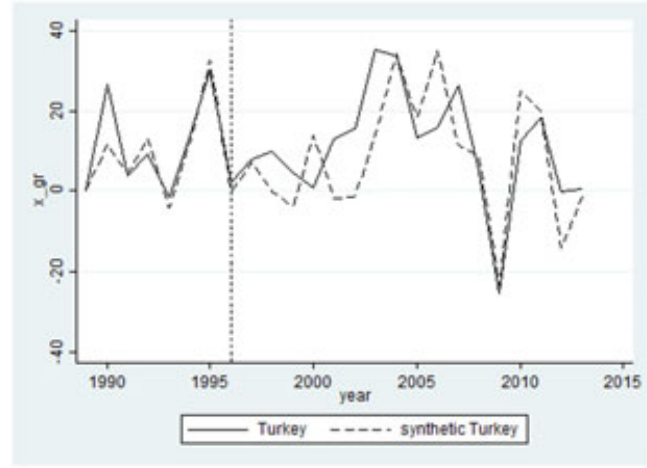

(a) Export Growth for Turkey

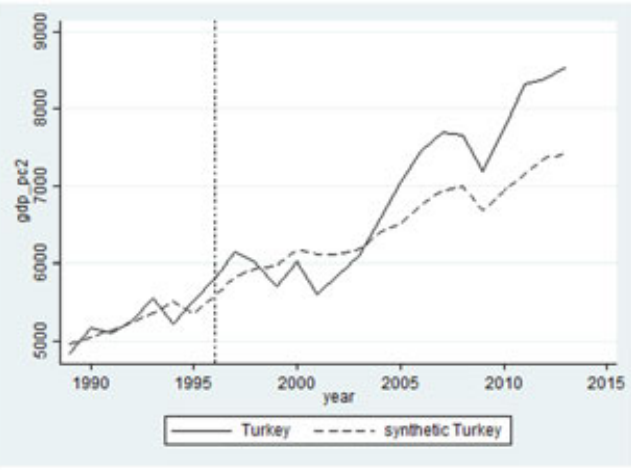

(b) GDP per capita for Turkey

especially after 2005, if the country had not been part of the CU. These results are similar to the results in the first case.

To account for the cumulative effect of reduction of export to the EU and GDP per capita in 2013, we used numbers illustrated in Appendix Figure. The calculation results indicate that Turkey would have experienced a lower level of exports to the EU and lower GDP per capita in the absence of the EU-Turkey CU. Specifically, Turkey's exports to EU countries in 2013 would have been lower by 38\%. Hence, Turkish exports to the EU would have been 39.4 million USD instead of 63.6 million USD in 2013. Moreover, real GDP per capita would have been USD 7,418 instead of USD 8,540 as of 2013. To put it another way, Turkey's total exports and real GDP per capita would have been $16 \%$ and $13 \%$ less in 2013, respectively.

In order to check the robustness of our estimates, we run placebo tests to see whether our results could have been driven by chance. The main question here is whether we would have estimated similar effects if we had chosen a random country included in the dataset. Following Abadie and Gardeazabal (2003) and Abadie et al. (2010), we applied the SCM to countries that did not become a part of the CU. If the placebo studies generated similar results to Turkey, then the increase in growth of exports and GDP per

Table 3: Predictor Balance for GDP per capita.

Variable
GDP per capita(1989-1991)
GDP per capita(1992-1995)
Current Account Balance/GDP(1990)
Invsetment/GDP(1990)
Population Growth(1995)
Industry Value Added/GDP(1991)
Schooling(1995)
Inflation(1992)

Actual
5384.53
5030.54
-1.3
23.66
1.9
32.69
5.5
65.2

Synthetic 5363.2 5049.24

$-1.52$ 
capita would have been driven by other factors than by the $\mathrm{CU}$. If not, our results provide significant evidence of the positive effect of the CU.

For the robustness tests, we choose the two countries with the largest weights in the synthetic controls for Turkey. The countries with the largest weights for export growth and GDP per capita are Chile and Indonesia, and Mexico and South Africa, respectively.

Figure 2 shows the gap in growth of exports for Turkey, Chile and Indonesia. It seems that the gap is bigger in the pre-intervention period and smaller in the post-intervention period for Chile and Indonesia. On average, Turkey's actual exports grow 2.67 percentage points more than the synthetic control, and Chile's and Indonesia's actual exports grew 1.22 and 3.53 percentage points less than their synthetic controls do. On the other hand, the gap for Turkey is smoother compared to the control countries. As we mentioned above, it is vital to mimic the actual export growth in the pre-intervention period. Another way to assess the performance of the optimization period is to look at the RSMPEs. Table 4 reveals that the RSMPE for Turkey is 6.11. In contrast, the RSMPEs for Chile and Indonesia are 28.13 and 17.56, respectively. One final way to evaluate the significance of our results is to look at the ratios of post-/pre-intervention RSMPEs. This ratio is 1.84 for Turkey, which is at least two times larger than the ratios for Chile and Indonesia, which are 0.87 and 0.64 , respectively. Based on the placebo tests, we can confirm that our results are robust for export growth.

The placebo tests for GDP per capita are shown in Figure A1. First, the gap in GDP per capita for Turkey is smooth during the pre-intervention period and increases in the postintervention period. As shown in Table 4, the average gap for Turkey is USD 379. While the gap is negative for Mexico, it is USD 763 for South Africa. Although there might seem to be a bigger effect for South Africa, we need to check the pre- and postintervention RSMPEs. The former for Turkey is smaller than for both control countries, which indicates that the optimization performance is better for Turkey. On the other hand, the ratio of the post-/pre-intervention RSMPE is at least four times bigger for Turkey. The exact ratios are 3.80, 0.48 and 0.98 , respectively. In parallel to the above placebo test, our estimations provide significant and robust results for GDP per capita as well.

Figure 2: Placebo Tests. [Colour figure can be viewed at wileyonlinelibrary.com]

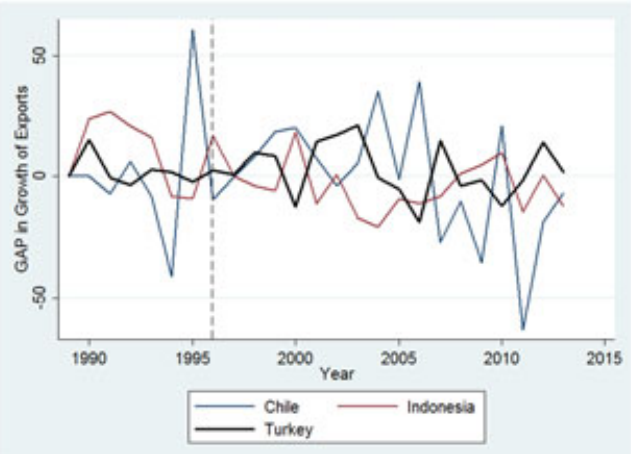

(a) Export growth for Turkey

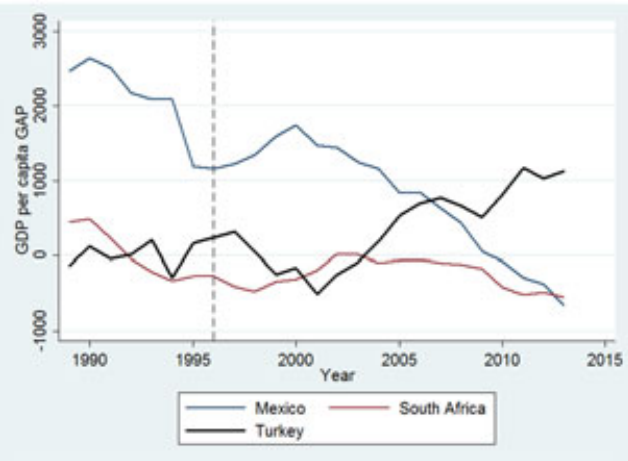

(b) GDP per capita for Turkey 
Table 4: Placebo Test Results.

\begin{tabular}{lrrcccc}
\hline & \multicolumn{3}{c}{ Growth of Exports } & \multicolumn{3}{c}{ GDP per capita } \\
& Turkey & Chile & Indonesia & Turkey & Mexico & South Africa \\
pre-intervention RSMPE & 6.11 & 28.13 & 17.56 & 164.19 & 2211.92 & 320.19 \\
post-intervention RSMPE & 11.24 & 24.42 & 11.29 & 623.68 & 1053.41 & 315.35 \\
post/pre-intervention RSMPE & 1.84 & 0.87 & 0.64 & 3.8 & 0.48 & 0.98 \\
Average GAP & 2.67 & -1.22 & -3.53 & 380 & 253.79 & 763.61 \\
\hline
\end{tabular}

\section{Conclusion}

This paper studying the 1995 EU-Turkey CU delivers a quantitative assessment of the trade and GDP effects of the EU-Turkey CU on the Turkish economy. Our SCM based analysis reveals, contrary to the results of most studies in the literature, that the CU's effects on Turkey's exports to EU countries and on Turkey's GDP per capita have been substantial by any standards.

We estimate what the levels of Turkish exports to the EU and GDP per capita in Turkey would have been if the EU-Turkey CU had not been formed. The obtained results show that Turkey would have experienced a lower level of exports and GDP per capita in the absence of the EU-Turkey CU. Our results indicate that Turkey's exports to the EU and Turkish GDP per capita could have been 38 per cent and 13 per cent less, respectively.

\section{Appendix A: Data}

The real GDP series for selected countries (measured in 2005 USD terms) are obtained from the World Development Indicators (WDI) online database provided by the World Bank. The other two variables - area and distance - come from the Centre for International Prospective Studies (CEPII) website. Bilateral distance is calculated according to the great circle formula using the geographic coordinates of the most important and crowded cities of those countries. The export values of selected countries to EU members in USD are obtained from the United Nations Comtrade Database, which measures merchandise trade, excluding services trade. The series on real GDP per capita measured in 2005 USD is taken from the WDI database. Share of industry and investment in GDP, population growth rate, current account balance-to-GDP, and inflation rate come from the International Financial Statistics Dataset of the International Monetary Fund. Finally, data on the average number of years of education received by people ages 25 years and older come from the International Human Development Indicators, provided by the United Nations Development Program.

The dataset covers the above-mentioned variables for Turkey and for the 18 countries similar to Turkey for the period 1989 to $2013 .^{8}$ The frequency of all the time-variant variables is annual.

\footnotetext{
${ }^{8}$ The selected countries are Argentina, Brazil, Chile, China, Colombia, India, Indonesia, Israel, Malaysia, Mexico, Pakistan, Peru, Philippines, Republic of Korea, Russia, South Africa, Thailand and Ukraine.
} 
Figure A1: Turkey's Exports to the EU. [Colour figure can be viewed at wileyonlinelibrary.com]

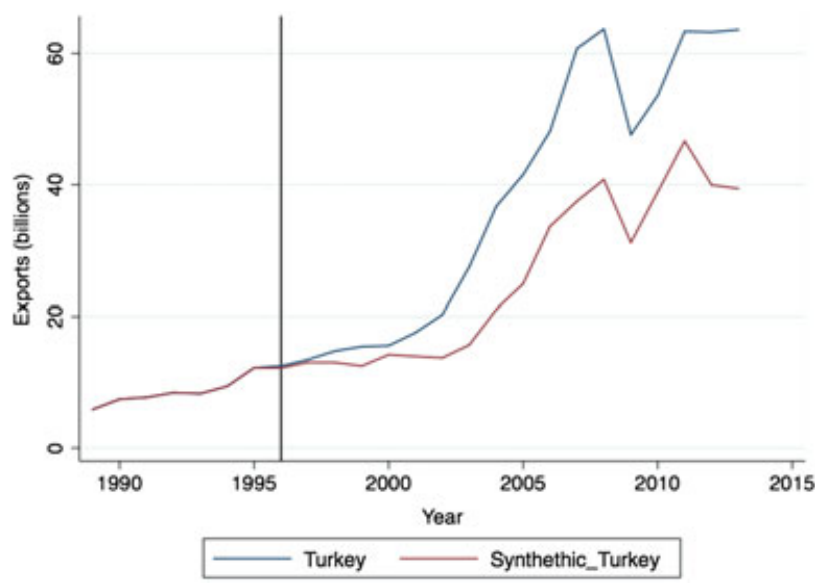

Correspondence:

Professor Sübidey Togan

Bilkent University

Department of Economics

06800 Bilkent, Ankara

Turkey

email: togan@bilkent.edu.tr

\section{References}

Abadie, A. and Gardeazabal, J. (2003) 'The Economic Costs of Conflicts: A Case Study of the Basque Country'. American Economic Review, Vol. 93, No. 1, pp. 113-132.

Abadie, A., Diamond, A. and Hainmueller, J. (2010) 'Synthetic Control Method for Comparative Case Studies: Estimating the Effects of California's Tobacco Control Program'. Journal of the American Statistical Association, Vol. 105, No. 490, pp. 493-505.

Adam, A. and Moutos, T. (2008) 'The Trade Effects of the EU-Turkey Customs Union'. The World Economy, Vol. 31, No. 5, pp. 685-700.

Anderson, J.E. and Van Wincoop, E. (2003) 'Gravity and Gravitas: A Solution to the Border Puzzle'. American Economic Review, Vol. 93, No. 3, pp. 170-192.

Antonucci, D. and Manzocchi, S. (2006) 'Does Turkey have a Special Trade Relation with the EU? A Gravity Model Approach'. Economic Systems, Vol. 30, No. 2, pp. 157-169.

Barro, R.J. (1991) 'Economic Growth in a Cross Section of Countries'. The Quarterly Journal of Economics, Vol. 106, No. 2, pp. 407-443.

Bilici, Ö., E. Erdil and İ. H. Yetkiner (2008) 'The Determining Role of EU in Turkey's Trade Flows: A Gravity Model Approach', Izmir University of Economics Working Papers in Economics.

Billmeier, A. and Nannicini, T. (2013) 'Assessing Economic Liberalization Episodes: A Synthetic Control Approach'. The Review of Economics and Statistics, Vol. 95, No. 3, pp. 983-1001.

European Commission (2015) 'Turkey 2015 Report', Communication from the Commission to the European Parliament, the Council, the European Economic and Social Committee and the Committee of the Regions, SWD(2015) 216 final, 10 November, Brussels. 
Glick, R. and Rose, A.K. (2002) 'Does a Currency Union affect Trade? The Time-Series Evidence'. European Economic Review, Vol. 46, No. 6, pp. 1125-1151.

Harrison, G.W., Rutherford, T.F. and Tarr, D.G. (1997) 'Economic Implications for Turkey of a Customs Union with the European Union'. European Economic Review, Vol. 41, No. 3, pp. $861-870$.

Karakas, C. (2013) 'EU-Turkey: Integration without Full Membership or Membership without Full Integration? A Conceptual Framework for Accession Alternatives'. JCMS, Vol. 51, No. 6, pp. 1057-1073.

Lee, W.S. (2011) 'Comparative Case Studies of the Effects of Inflation Targeting in Emerging Economies'. Oxford Economic Papers, Vol. 63, No. 2, pp. 375-397.

Lejour, A.M. and de Mooij, R.A. (2005) 'Turkish Delight: Does Turkey's Accession to the EU Bring Economic Benefits?' Kyklos, Vol. 58, No. 1, pp. 87-120.

Longo, R. and Sekkat, K. (2004) 'Economic Obstacles to Expanding Intra-African Trade'. World Development, Vol. 32, No. 8, pp. 1309-1321.

Magee, C.S.P. (2015) 'Trade Creation, Trade Diversion, and the General Equilibrium Effects of Regional Trade Agreements: A Study of the European Community-Turkey Customs Union'. Review of World Economics, Vol. 152, No. 2, pp. 383-399.

Mercenier, J. and Yeldan, E. (1997) 'On Turkey's Trade Policy: Is a Customs Union with Europe Enough?’ European Economic Review, Vol. 41, No. 3, pp. 871-880.

Neyaptı, B., Taşkın, F. and Üngör, M. (2007) 'Has European Customs Union Agreement really Affected Turkey's Trade?' Applied Economics, Vol. 39, No. 16, pp. 2121-2132.

Nowak-Lehmann, F., Herzer, D., Martinez-Zarzoso, I. and Vollmer, S. (2007) 'The Impact of a Customs Union between Turkey and the EU on Turkey's Exports to the EU'. JCMS, Vol. 45, No. 3, pp. 719-743.

Soloaga, I. and Winters, L.A. (2001) 'Regionalism in the Nineties: What Effect on Trade?' North American Journal of Economics and Finance, Vol. 12, No. 1, pp. 1-29.

Togan, S. (1997) 'Opening up the Turkish Economy in the Context of the Customs Union with EU'. Journal of Economic Integration, Vol. 12, No. 2, pp. 157-179.

Ugur, M. (2010) 'Open-Ended Membership Prospect and Commitment Credibility: Explaining the Deadlock in EU-Turkey Accession Negotiations'. JCMS, Vol. 48, No. 4, pp. 967-991.

World Bank (2014) 'Evaluation of the EU-Turkey Customs Union', World Bank Report No. 85830-TR. 